\title{
Sistem Administrasi Penjualan Berbasis Web Pada PT. Surya Mustika Nusantara Cabang Serang
}

\author{
${ }^{1}$ Po. Abas Sunarya, ${ }^{2}$ Achmad Rachmat $S,{ }^{3}$ Firda Nopia Andini \\ ${ }^{1}$ Program Studi Manajemen Retail Universitas Raharja, ${ }^{2}$ Program Studi Komputerisasi Akuntansi \\ Universitas Raharja, ${ }^{3}$ Program Studi Sistem Informasi Universitas Raharja \\ E-mail: ${ }^{1}$ abas@ @raharja.Info, ${ }^{2}$ achmad.rachmat@ raharja.info, ${ }^{3}$ firda.nopia@ raharja.info
}

\begin{abstract}
Abstrak
PT. Surya Mustika Nusantara berdiri pada tahun 2007 dan terletak di Komplek Purna Bakti Kp. GuruguiSerang Barat adalah Perusahaan yang bergerak dalam bidang pendistribusian produk tembakau seperti Apache dan Camel yang didistribusikan oleh sales. PT Surya Mustika Nusantara Cabang Serang pada sistem administrasi penjualannya masih menggunakan cara manual belum adanya sistem berbasis web, yaitu dengan memanfaatkan microsoft excel dan proses pembuatan laporan penjualan dilakukan setelah adanya laporan dari sales yang biasanya akan dilaporkan setelah proses pendistribusian ke setiap toko, akibatnya terdapat beberapa kendala seperti proses pendataan yang memakan waktu lama dan proses pelaporan transaksi yang dilakukan oleh sales ke admin tidak real-time, kemungkinan terjadinya redudansi data, dan pencarian data yang dibutuhkan memerlukan waktu yang cukup lama karena harus mencari didalam file microsoft excel atau ditumpukan kertas yang bahkan mungkin rusak. Hasil analisis dan dilakukannya observasi pada PT. Surya Mustika Nusantara Cabang Serang menemukan beberapa masalah yang ada dalam sistem yang berjalan, maka penulis mengajukan untuk dirancangnya sistem administrasi penjualan yang baru berbasis Web. Menggunakan metode analisis CSF (Critical Success Factors). Perancangan sistem menggunakan metode analisa berorientasi objek dengan Unified Modeling Language (UML), Dengan adanya usulan pembaruan sistem adminisreasi penjualan pada PT. Surya Mustika Nusantara Cabang Serang, proses administrasi penjualan yang berjalan akan lebih baik lagi.
\end{abstract}

Kata Kunci: Sistem Administrasi Penjualan, Sales, Admin, PT. Surya Mustika Nusantara Cabang Serang

\begin{abstract}
PT. Surya Mustika Nusantara was established in 2007 and is located in Purna Bakti Kp. Gurugui-Serang Barat Complex is a company engaged in the distribution of tobacco products such as Apache and Camel distributed by sales. PT Surya Mustika Nusantara Serang Branch in its sales administration system still uses manual means of the absence of a web-based system, namely by utilizing microsoft excel and the process of making sales reports is done after the sales report that will usually be reported after the distribution process to each store, as a result there are some obstacles such as the data collection process that takes a long time and the transaction reporting process carried out by sales to admins. Not realtime, the possibility of data redundancies, and the search for data that is needed takes a long time because it has to search in microsoft excel files or stacked with paper that may even be damaged. The results of the analysis and observations at PT. Surya Mustika Nusantara Serang Branch found some problems that exist in the running system, so the author proposed for the design of a new Web-based sales administration system. Using the CSF (Critical Success Factors) analysis method. System design using object-oriented analysis methods with Unified Modeling Language (UML), with the proposed update of the sales administration system at PT. Surya Mustika Nusantara Serang Branch, the sales administration process that runs will be even better.
\end{abstract}

Keywords: Sales Administration System, Sales, Admin, PT. Surya Mustika Nusantara Cabang Serang

Vol 8 No 1 - Februari 2022 


\section{PENDAHULUAN}

Salah satu perkembangan teknologi yang penting adalah semakin diperlukannya penggunaan alat untuk pengolahan data yang berfungsi untuk menghasilkan informasi, menyimpan data, seperti komputer. Selain itu komputer juga dapat memudahkan proses administrasi penjualan yang memiliki peranan dalam menemukan kesalahan data yang diolah dan dapat memudahkan pekerjaan manusia sehingga keterlambatan suatu pekerjaan dapat dihindari. Administrasi menurut Siagian (2016) ${ }^{[1]}$, "Administrasi sebagai keseluruhan proeses kerja sama antara dua orang manusia atau lebih yang di dasarkan atas rasionalitas tertentu untuk mencapai tujuan dan sasaran yang telah ditentukan sebelumnya." Sedangkan penjualan menurut Francis Tantri dan Thamrin $(2016: 3)^{[2]}$. "Penjualan adalah bagian dari promosi dan promosi adalah salah satu bagian dari keseluruhan System pemasaran." Maka administrasi penjualan adalah proses pencatatan datadata atau surat menyurat yang dilakukan untuk menunjang proses kegiatan penjualan atau promosi untuk mecapai suatu tujuan yang telah ditentukan sebelumnya terhadap suatu organisasi atau perusahaan.

PT Surya Mustika Nusantara berdiri pada tahun 2007 yang terletak di Komplek Purna Bakti Kp. Gurugui-Serang Barat adalah Perusahaan yang bergerak dalam bidang pendistribusian produk tembakau seperti Apache dan Camel yang didistribusikan oleh sales. PT Surya Mustika Nusantara Cabang Serang pada sistem administrasi penjualannya masih menggunakan cara manual belum adanya sistem berbasis web, yaitu dengan memanfaatkan microsoft excel dan proses pembuatan laporan penjualan dilakukan setelah adanya laporan dari sales yang biasanya akan dilaporkan setelah proses pendistribusian ke setiap toko, akibatnya terdapat beberapa kendala seperti proses pendataan yang memakan waktu lama dan proses pelaporan transaksi yang dilakukan oleh sales ke admin tidak real-time, kemungkinan terjadinya redudansi data, dan pencarian data yang dibutuhkan memerlukan waktu yang cukup lama karena harus mencari didalam file microsoft excel atau ditumpukan kertas yang bahkan mungkin rusak.

Untuk itu dengan adanya perancangan dan penerapan sistem komputerisasi yang dapat membantu aktivitas administrasi penjualan menjadi lebih efisien. Menurut Nadeak, dkk (2016:54) ${ }^{[3]}$, "Perancangan adalah langkah awal dalam pengembangan suatu sistem yang bertujuan untuk mendefinisikan sebuah peralatan, satu proses atau satu sistem secara detail yang membolehkan dilakukan realisasi fisik." Selain diperlukannya perancangan yang baik dibutuhkan sistem juga yang dapat menunjang proses administrasi penjualan, menurut Hesty dkk $(2017: 66)^{[4]}$, "Sistem adalah sekumpulan subsistem yang saling berhubungan dan bergantunga satu sama lain, bekerja sama untuk mencapai suatu tujuan yang sudah ditetapkan sebelumnya." Adapun penelitian yang sebelumnya dilakukan oleh Sri Rahayu, Zainul Hakim, Nurul Septiana, dalam Jurnal Sisfotek Global Volume 9 No.2 (2019) ${ }^{[5]}$, mengenai "Sistem Informasi Administrasi Penjualan Dan Jasa Air Conditioner (Ac)". Peneliti membahas tentang sistem informasi administrasi penjualan, pada sistem informasi administrasi yang sedang berjalan masih bersifat manual dan masih sangat sederhana terutama dalam memberikan informasi mengenai data permintaan pelanggan, penjualan dan laporan hasil pelayanan jasa yang diberikan. Karena permasalahan tersebut maka dibutuhkan suatu rancangan sistem yang dapat membantu dalam pengelolaan administrasi penjualan tersebut. Metodologi yang digunakan yaitu SDLC (System Development Life Cycle) dan juga penelitian yang dilakukan oleh Igo Fajar Nugraha, dalam Jurnal Semnas Ristek Vol 5, No $1(2021)^{[6]}$, mengenai "Perancangan Aplikasi Administrasi Penjualan Sparepart Dan Service Pada Cv. Performa Motor". Pencatatan administrasi penjualan yang dilakukan oleh C.V Performa Motor hingga saat ini masih menggunakan cara manual, sehingga sering terjadi kesalahan atau human error. Oleh karena itu, tujuan dari penelitian ini adalah untuk merancang sistem/aplikasi administrasi penjualan berbasis Java NetBeans yang akan digunakan oleh CV Performa Motor. Wawancara, observasi, dokumentasi, dan studiliteratur dilakukan pada penelitian ini sebagai studi pendahuluan. Penelitian ini menggunakan metode kualitatif dan metode SDLC (Software Development Life Cycle), dengan model waterfall. Penelitian ini menghasilkan sistem yang digunakan untuk administrasi penjualan berbasis Java NetBeans, sehingga memudahkan pelaku usaha dalam pengelolaan administrasi. 
Maka dengan membangun sistem administrasi penjualan yang baik yaitu dengan meningkatkan sistem administrasi penjualan yang memiliki kecepatan dan keakuratan sehingga bisa mendapatkan informasi yang dibutuhkan secara efisien (Genrawan Hoendarto, dkk. 2017) ${ }^{[7]}$. Maka diperlukan suatu strategi yang lebih baik dengan cara merancang suatu sistem administrasi penjualan berbasis web yang dapat membantu proses administrasi penjualan ini menjadi lebih efisien dan mengetahui laporan penjualan yang lebih mudah dibuat, serta data yang disimpan lebih aman karna tersimpan didalam database.

\section{METODE PENELITIAN}

Metode yang digunakan peneliti dalam penelitian ini adalah:

\subsection{Metode Pengumpulan Data}

Dalam pengumpulan data peneliti menggunakan beberapa metode peeletian yang pertama menggunakan metode metode observasi yaitu dengan mempeoleh data dari teknik pengumpulan data terhadap masalah yang ada dengan mengadakan pengamatan secara langsung pada PT. Surya Mustika Nusantara Cabang Serang dengan mengumpulkan data dibagian administrasi penjualan yang berhubungan dengan pengolahan data penjualan, baik yang berupa laporan transaksi ataupun laporan penjualan sehingga memperoleh data yang akurat, selanjutnya peneliti melakukan metode Wawancara (Interview) untuk memperoleh data dengan cara memberikan pertanyaan-pertanyaan seputar administrasi penjualan secara langsung dengan stakeholder PT. Surya Mustika Nusantara Cabang Serang. Dalam melakukan proses wawancara ini penulis bertanya langsung dengan Bapak Adi Nurhadi sebagai supervisior dan yang memahami proses administrasi penjualan dan selaku stakeholder PT. Surya Mustika Nusantara Cabang Serang. Setelah melakukan metode observasi dan wawancara peneliti melakukan studi pustaka dengan mengumpulkan data - data yang berhubungan dengan penelitian dan mencari informasi lewat buku tentang administrasi penjualan atau yang berkaitan dengan penjualan, dan literatur atau jurnal lainnya yang berkaitan dengan administrasi atau penjualan bertujuan untuk menambah refrensi dan membentuk landasan teori.

\subsection{Metode Analisa}

Metode analisa yang digunakan yaitu dengan menggunakan metode analisa CFS (Critical Success Factors) merupakan suatu metode analisa yang mengidentifikasikan faktor-faktor pendukung keberhasilan secara lebih jelas untuk menentukan suatu aktivitas yang harus dilakukan dan infomasi apa yang dibutuhkan dalam suatu perusahaan atau organisasi untuk mencapi tujuan. Selain itu peneliti menggunakan Unified Modelling Language (UML) sebagai salah satu alat untuk menggambarkan visualisasi sistem yang berorientasi pada objek yang terdiri dari beberapa diagram, dan peneliti juga menggunakan metode elisitasi untuk menentukan kebutuhan user yang diharapkan bisa meningkatkan sistem yang sudah ada.

\subsection{Metode Perancangan}

Dalam penelitian ini penulis menggunakan metode perancangan sistem Unified Modelling Language (UML) dengan menggunakan diagram seperti: Use Case Diagram, Sequence Diagram, dan Activity Diagram. Pada proses pembuatan program dalam proses perancangan sistem menggunakan bahasa pemrograman, PHP (PHP: Hypertext Preprocessor), MySQL sebagai database server dan VS Code sebagai text editor.

\section{HASIL DAN PEMBAHASAN}

Dalam penelitian ini akan dijelaskan mengenai perancangan sistem administrasi penjualan berbasis web pada PT. Surya Mustika Nusantara cabang Serang, penulis mengusulkan untuk melaksanakan rancangan sistem baru yang dapat memperbaiki serta meningkatkan administrasi penjualan yang telah ada, yakni dengan merubah proses pembuatan laporan penjualan yang masih memanfaatkan Microsoft excel serta proses pelaporan penjualan yang masih manual menjadi berbasis web, sehingga mempermudah admin serta sales dalam melaksanakan proses administrasi penjualan pada PT. Surya 
Mustika Nusantara Cabang Serang. Berdasarkan hasil analisa kebutuhan-kebutuhan sistem yang sudah ditetapkan, hingga langkah- langkah selanjutnya ialah perancangan ataupun design sistem usulan yang bertujuan buat memperbaiki sistem yang lama.

\subsection{Analisa CSF (Critical Success Factors)}

Peneliti menggunakan metode analisa CSF (Critical Success Factors) merupakan metode yang mengidentifikasikan faktor-faktor pendukung keberhasilan suatu organisasi dan dapat menemukan metode yang cocok dalam merancang sistem merancang sistem administrasi penjualan menjadi lebih efisien. Faktor-faktor ini sangat penting bagi perusahaan untuk menentukan kebutuhan serta kendala yang dapat dijadikan acuan untuk merancang sistem administrasi penjualan menjadi lebih efisien. Berikut ini merupakan hasil dari analisa CSF (Critical Success Factors) yang telah dilakukan pada PT. Surya Mustika Nusantara, yaitu sebagai berikut:

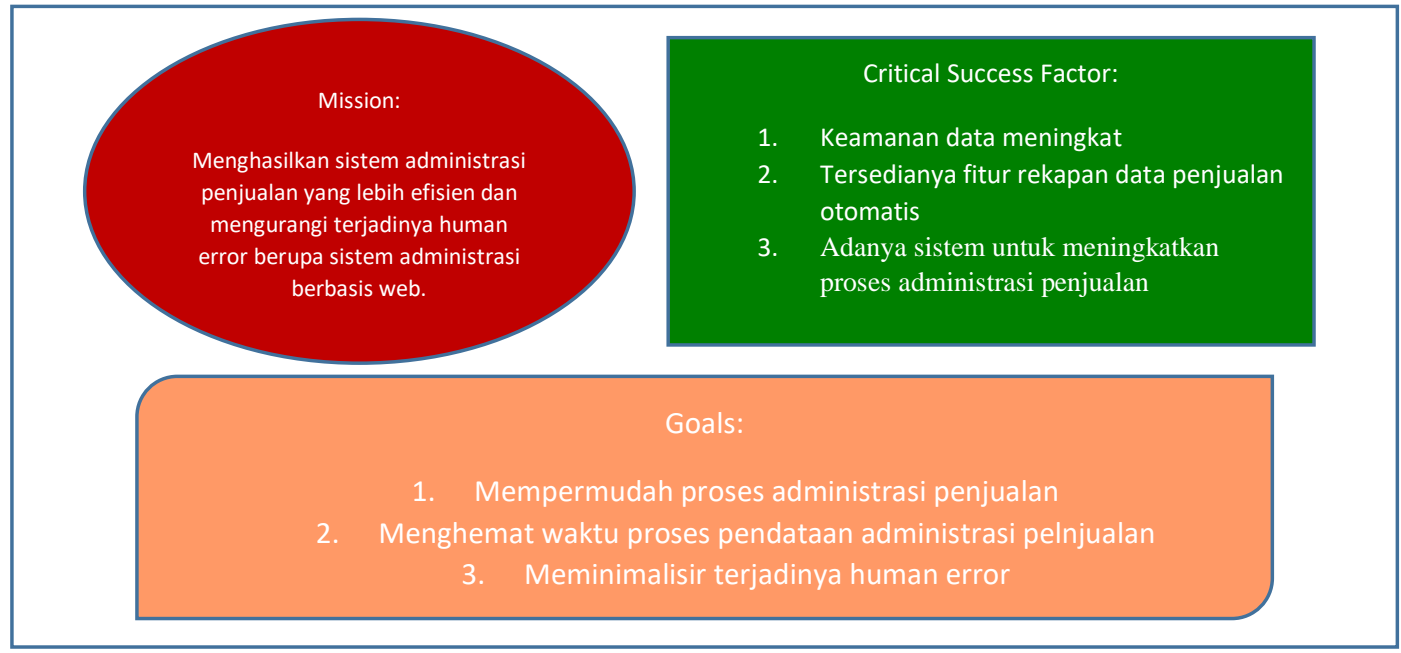

\section{Use Case Diagram}

Gambar dibawah ini adalah Use Case Diagram untuk menggambarkan secara umum sisetem administrasi penjualan sedang berjalan. Berdasarkan diagram tersebut terdapat 4 aktor, yaitu Admin, Sales, Kepala Gudang dan Area Manager yang memiliki 7 usecase dalam kegiatan administrasi penjualan yang sedang berjalan saat ini. 


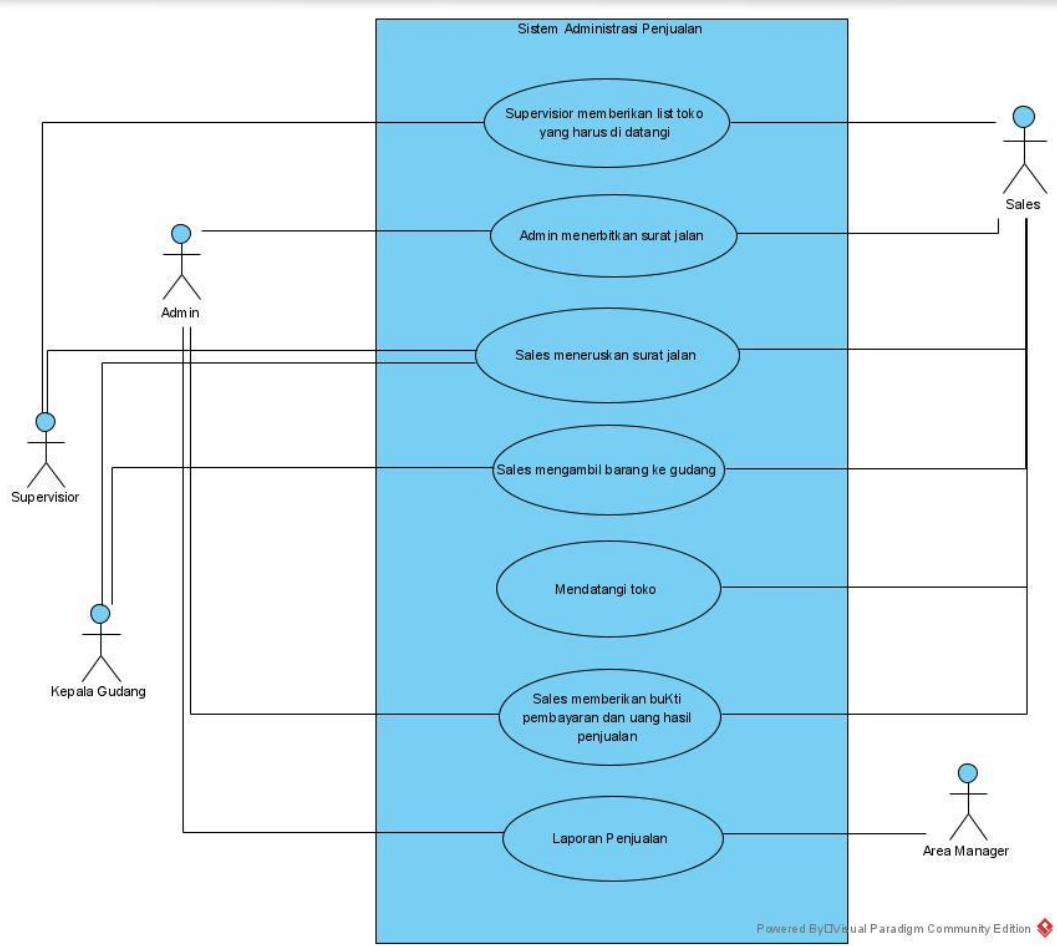

Gambar 2. Usecase diagram administrasi penjualan

\subsection{Rancangan Sistem}

Untuk mengatasi permasalahan yang ada pada sistem administrasi penjualan yang sedang berjalan, dibutuhkan sistem administrasi penjualan berbasis website, sehingga sistem usulan ini dapat memudahkan admin dalam pembuatan serta rekapan laporan penjualan, selain itu menjadikan pelaporan transaksi yang dilakukan sales menjadi real-time karna terhubung didatabase admin dan sudah berbasis website. Maka tidak perlu menunggu laporan dari sales yang biasanya dilakukan setelah melakukan pendistribusian ke setiap toko dengan begitu dapat mempercepat proses administrasi penjualan dalam hal pembuatan laporan penjualan, pengolahan data penjualan serta transaksi penjualan.

Berikut ini beberapa usulan pada sistem yang akan dirancang:

Sales:

1. Dapat melakukan login

2. Dapat mengakses website

3. Dapat melakukan input transaksi

4. Dapat log out website

Admin:

1. Dapat melakukan login

2. Dapat mengakses website

3. Dapat mengelola data pelanggan, sales dan stok barang

4. Dapat menginput surat jalan

5. Dapat menampilkan laporan penjualan

6. Dapat log out website 


\section{Usecase Diagram yang di usulkan}

Usecase diagram dibawah ini menggambarkan alur sistem beserta aktornya dalam rancangan sistem administrasi penjualan berbasis website.

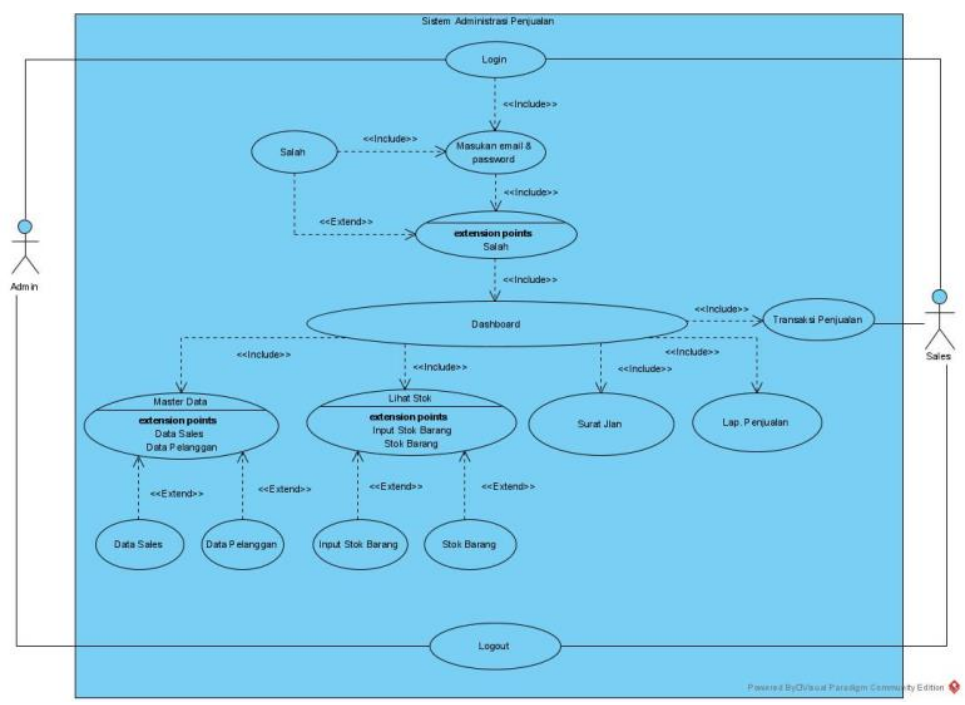

Gambar 3. Use Case yang diusulkan

Berdasarkan Gambar 3. Diatas dapat dijelaskan sebagai berikut:

a. 1 (satu) sistem rancangan usulan sistem administrasi penjualan.

b. 2 (dua) actor dalam kegiatan yaitu: Admin dan Sales.

c. 15 (lima belas) Use Case, yaitu : Login, Masukan Username \& Password, Validasi, Salah, Dashboard, Transaksi, Master Data, Data Sales, Data Pelanggan, Lihat stok, Input stok barang, stok Barang, Surat Jalan, Lap. Penjualan, Log Out.

\section{Activity Diagram yang diusulkan}

\section{Activity Diagram Sales}

Dibawah ini adalah runtunan proses atau aktivitas yang dilakukan oleh sales dari kegiatan rancangan sistem administrasi penjualan berbasis website.

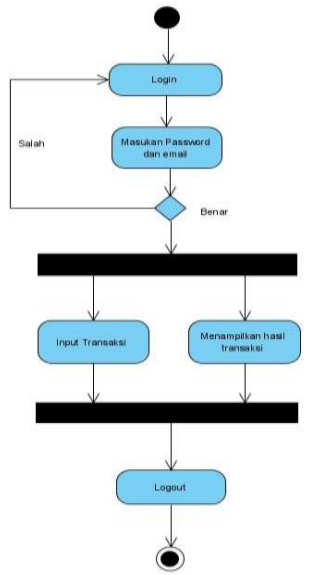

Gambar 4. Activity Diagram Sales

Berdasarkan gambar 4. Activity Diagram diatas, dapat diketahui:

1. 1 initial node merupakan awal proses kegiatan 
2. 5 Action state yang mencerminkan eksekusi suatu aksi

3. 2 Fork node, digunakan untuk memecahkan sebuah behavior menjadi activity paralel

4. 1 Join node, digunakan untuk menggabungkan kembali activity yang paralel

5. 1 Decision Node Digunakan untuk menggambarkan suatu keputusan yang harus diambil pada kondisi tertentu

6. 1 final node yang merupakan akhir proses kegiatan

\section{Activity Diagram Admin}

Dibawah ini adalah runtunan proses atau aktivitas yang dilakukan oleh admin dari kegiatan rancangan sistem administrasi penjualan berbasis website.

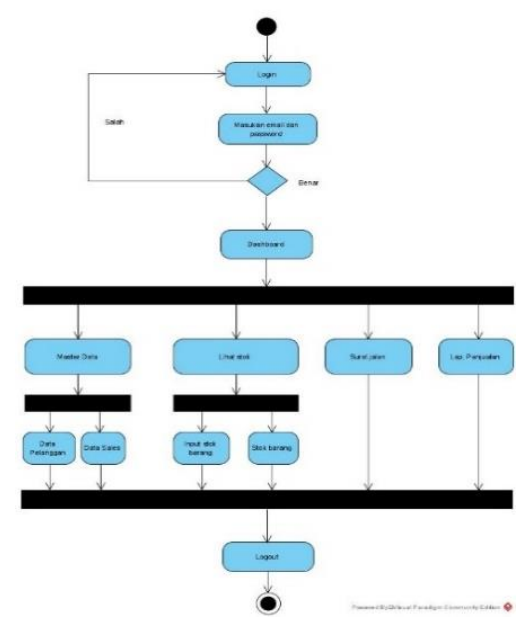

Gambar 5. Activity Diagram Admin

Berdasarkan gambar 5. Activity Diagram diatas, dapat diketahui:

1. 1 initial node merupakan awal proses kegiatan

2. 12 Action state yang mencerminkan eksekusi suatu aksi

3. 3 Fork node, digunakan untuk memecahkan sebuah behavior menjadi activity paralel

4. 1 Join node, digunakan untuk menggabungkan kembali activity yang paralel

5. 1 Decision Node Digunakan untuk menggambarkan suatu keputusan yang harus diambil pada kondisi tertentu

6. 1 final node yang merupakan akhir proses kegiatan 


\section{Sequence Diagram Admin}

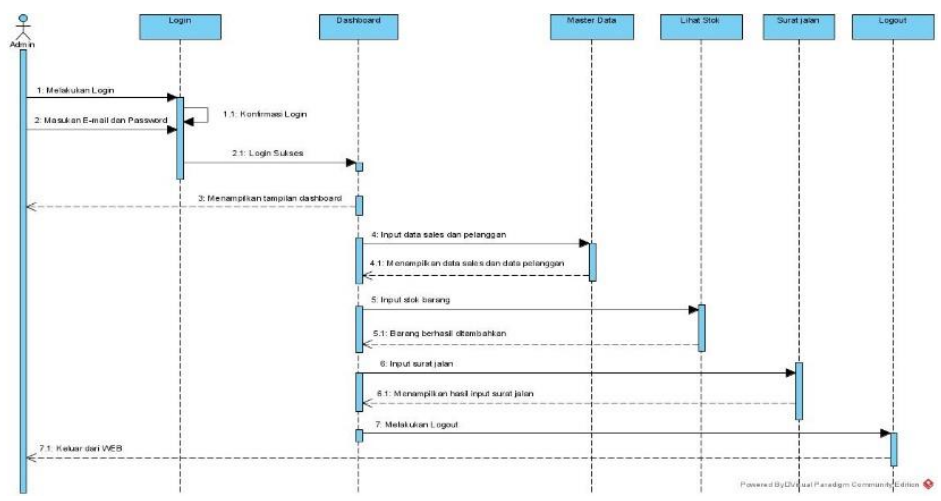

Gambar 6. Sequence Diagram Admin

Berdasarkan gambar 6. Sequence Diagram diatas, dapat diketahui:

1. 1 Actor yang melakukan kegiatan yaitu Admin

2. 6 Lifeline terdiri dari: Login, Dashboard, Master Data, Lihat Stok, Surat Jalan, Log Out

3. 13 Message memberikan informasi - informasi aktivitas yang berlangsung pada proses kegiatan yang dilakukan oleh actor tersebut

\section{Sequence Diagram Sales}

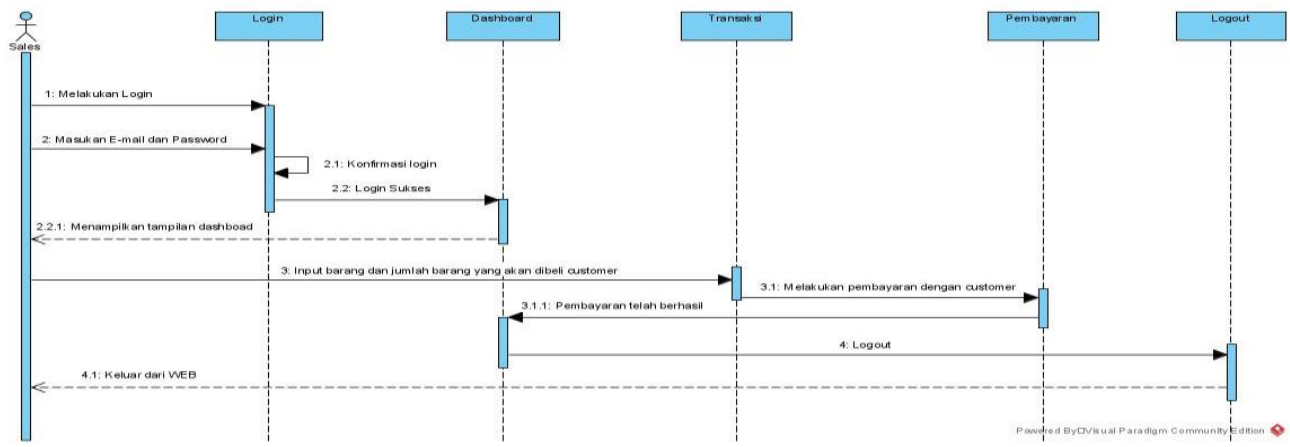

Gambar 7. Sequence Sales

Berdasarkan gambar 7. Diatas, dapat diketahui:

1. 1 Actor yang melakukan kegiatan yaitu Sales.

2. 5 Lifeline terdiri dari: Login, Dashboard, Transasksi, Pembayaran, Log Out.

3. 10 Message memberikan informasi - informasi aktivitas yang berlangsung pada proses kegiatan yang dilakukan oleh actor tersebut.

\section{Tampilan Rancangan Sistem}

Dibawah ini adalah tampilan dari rancangan sistem administrasi penjualan:

1. Tampilan Login 


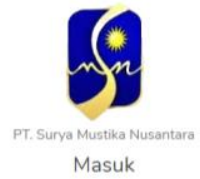

admin@gmail.com

Gambar 8. Halaman Login

Tampilan halaman login merupakan tampilan awal dengan memasukan email dan password sebelum Admin atau Sales menjalankan sistem ini.

2. Tampilan Dashboard

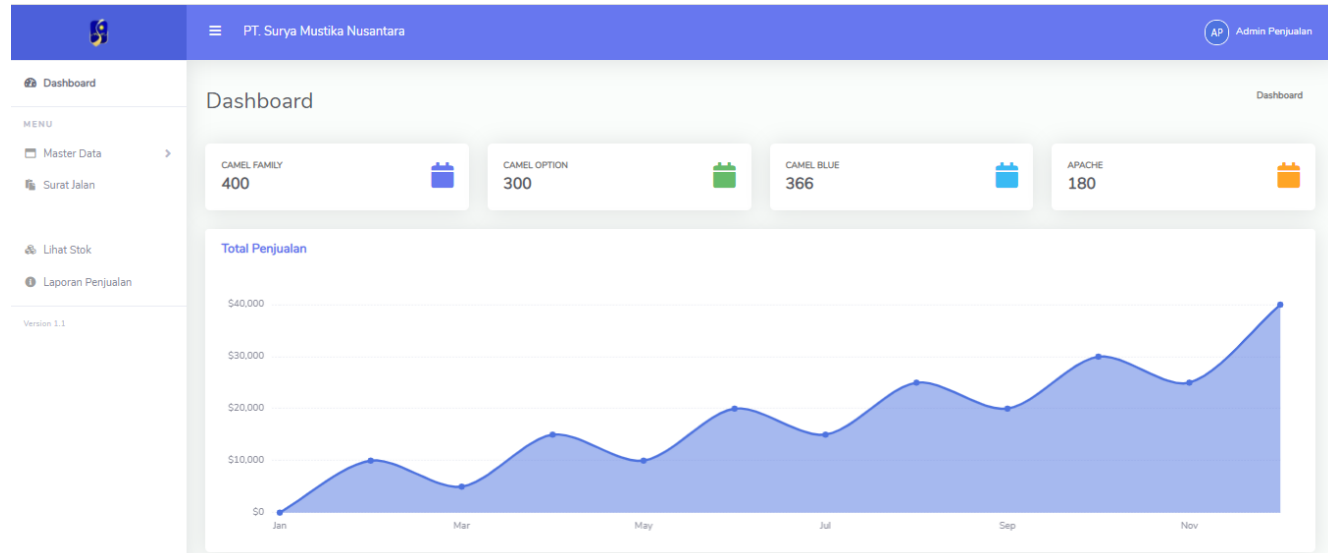

Gambar 9. Halaman Dashboard

Tampilan dashboard dari Admin yang telah berhasil melakukan login, dalam halaman ini terdapat beberapa menu yaitu Master data, dan Lap. Penjualan dll,

2. Tampilan Data Pelanggan

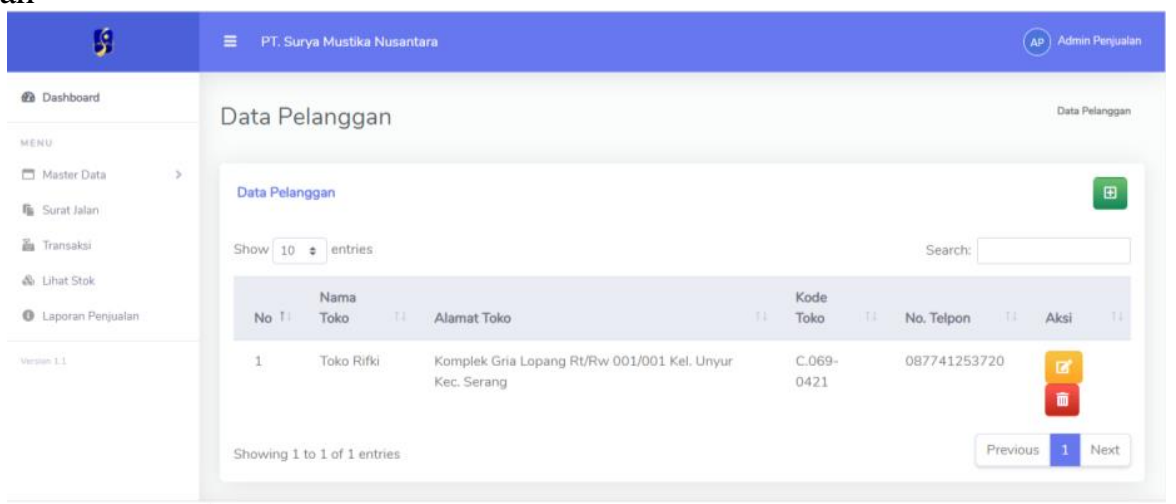

Gambar 10. Halaman Data Pelanggan

Halaman ini menampilkan data pelanggan yang admin input pada menu master data sebagai tempat penyimpanan data pelanggan. 
3. Tampilan Halaman Surat Jalan

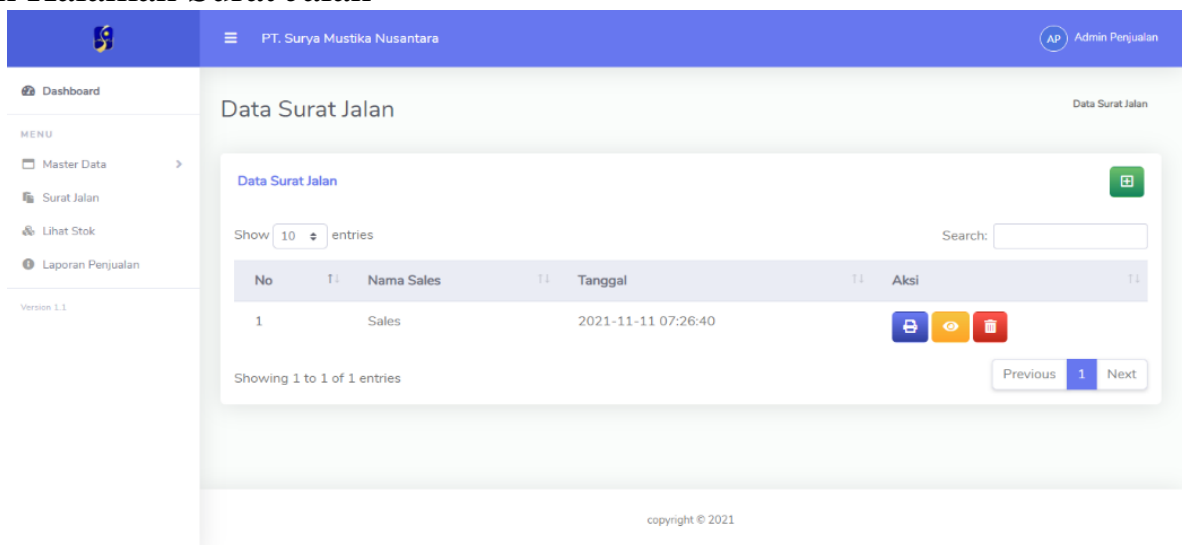

Gambar 11. Halaman Surat Jalan

Halaman ini menampilkan Surat jalan yang akan di input oleh admin dan terdapat 3 aksi yaitu print, lihat dan hapus.

4. Tampilan Halaman Laporan Penjualan

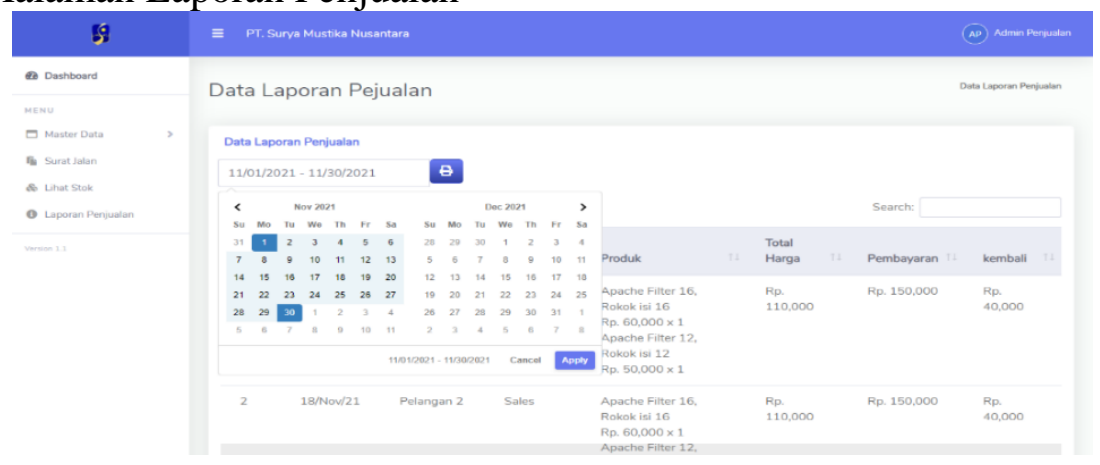

Gambar 12. Halaman Laporan Penjualan

Halaman ini menampilkan hasil laporan penjualan yang sales input setelah melakukan transaksi, dengan tampilan ini admin mendapatkan informasi yang real time tanpa harus menunggu laporan hasil penjualan dari sales.

5. Tampilan Halaman Transaksi Sales

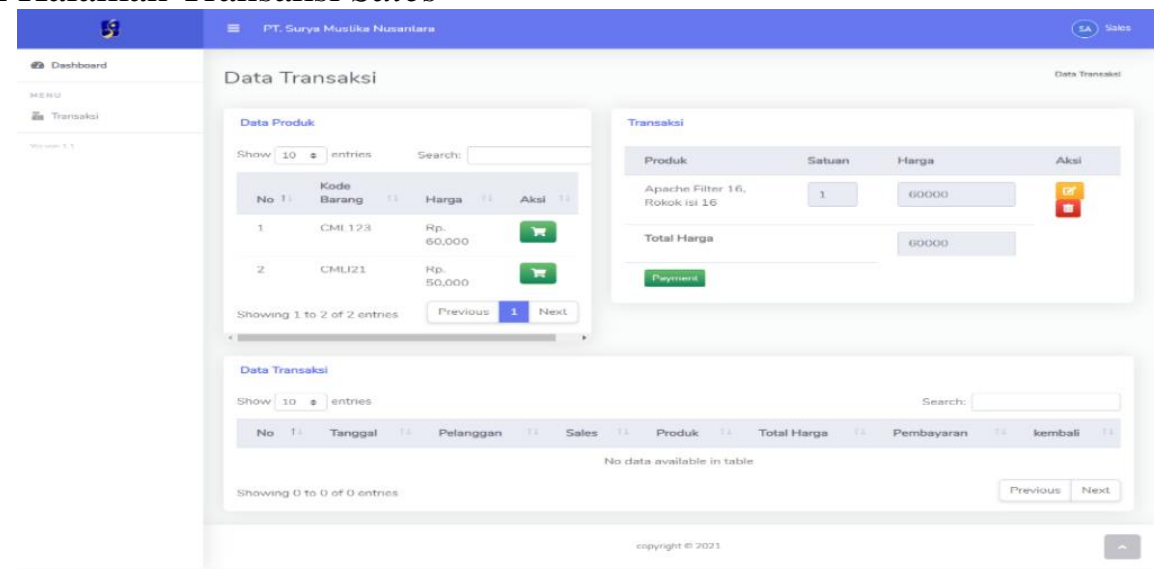

Gambar 13. Halaman Transaksi Sales 
Halaman ini menampilkan transaksi yang akan diinput oleh sales dalam melakukan penjualan barang ke customer.

\section{KESIMPULAN}

Dengan adanya sistem yang terkomputerisasi dari permasalahan ini dapat dirancangnya sistem administrasi penjualan agar dapat mempercepat proses pendataan pelanggan sales dll, mengurangi kemungkinan terjadinya redudansi data, dan pencarian data yang dibutuhkan tidak memerlukan waktu yang cukup lama lagi karena sudah tersimpan didatabase.

Selain itu dapat mempermudah sales dalam melakukan pelaporan penjualan dan tidak harus menunggu selesainya pendistibusian ke customer karna admin sudah bisa melihat transaksi apa saja yang telah dilakukan oleh sales secara rela-time sehingga sales tidak perlu melakukan pelaporan penjualan lagi.

\section{SARAN}

Dari kesimpulan tersebut penulis mempunyai beberapa saran yang dapat membantu agar rancangan sistem dapat terealisasikan dengan baik, agar didukungnya sistem yang akan dirancang dengan perangkat yang mendukung seperti hardware,software dan perlu dilakukan adanya sosialisasi terhadap Admin dalam proses administrasi penjualan agar dapat berjalan dengan baik.

\section{DAFTAR PUSTAKA}

[1] S. Siagian, Manajemen Penjualan. Yogyakarta: BPFE Yogyakarta

[2] Abdullah, Thamrin \& Francis Tantri. 2016. Manajemen Pemasaran Jakarta: Rajawali Pers

[3] Nadeak, Berto. Abbas Parulian. Pristiwanto dan Saidi Ramadan Siregar. 2016. Perancangan aplikasi pembelajaran internet dengan menggunakan metode computer based instruction. Medan: STMIK Budi Darma Journal Riset Komputer (JURIKOM). ISSN 2407-389X. Vol. 3, No.

[4] Sari, Hesty Puspita dkk. 2017. "Sistem Aplikasi Pengolahan Nilai Raport SDN Tanjunganom 2 Kecamatan Tanjunganom Nganjuk". Jurnal Ilmiah Teknik Informatika Vol 11 No

[5] Rahayu sri, Hakim Zainul, Septiana Nurul, Jurnal Sisfotek Global Volume 9 No.2 (2019) mengenai "SISTEM INFORMASI ADMINISTRASI PENJUALAN DAN JASA AIR CONDITIONER (AC)".

[6] Nugraha Igo Fajar, Jurnal Semnas Ristek Vol 5, No 1 (2021) mengenai "PERANCANGAN APLIKASI ADMINISTRASI PENJUALAN SPAREPART DAN SERVICE PADA CV. PERFORMA MOTOR".

[7] Hoendarto Genrawan, Willay Thommy, Mulianto Dedy. (2017). Perancanga Sistem Administrasi Penjualan. (Jurnal InTekSis Vol 3, No 2 (2017)). 